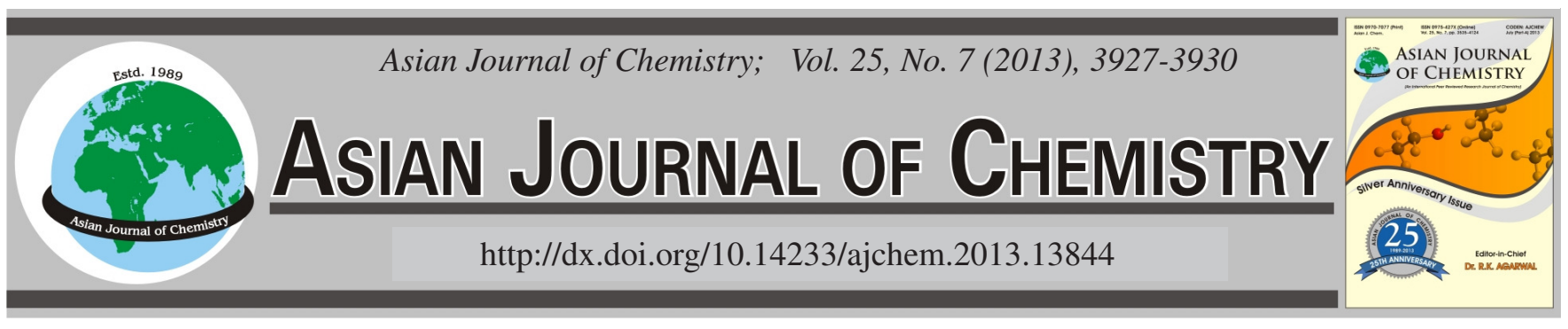

\title{
Adsorption Thermodynamics, Kinetics and Mechanism of Calcium(II) Ions onto Kaolinite Clay in Coal Slime Water
}

\author{
L. FENG ${ }^{*}$, H.Y. TANG, J.T. LiU and L.L. Song
}

School of Chemical Engineering and Technology, China University of Mining and Technology, Xuzhou 221116, Jiangsu Province, P.R. China *Corresponding author: Fax: +86 516 83591059; Tel: +86 516 83591059; E-mail: cumthgfl@ 163.com

\begin{abstract}
Slime water is a highly concentrated micro-solid-liquid suspension-dispersion system which is mainly consisted of kaolinite and other clay minerals. The existence of these fine clay particles is one of the reasons why slimes water is difficult to clarify. In this work, the adsorption thermodynamics, kinetics and mechanism of $\mathrm{Ca}^{2+}$ onto kaolinite clay were systematically investigated through batch adsorption experiments, theoretical analysis, characterization of sorbents and field trial. The results show that the adsorption nature of $\mathrm{Ca}^{2+}$ onto kaolinite is spontaneous and exothermic. The adsorption data follow Langmuir isotherms. The possible adsorption mechanism is that $\mathrm{CaOH}^{+}$in the system reacted with $\equiv \mathrm{SiOH}$ and $>\mathrm{AlOH}$ groups appeared in the surface of kaolinite. Sorption is mainly controlled by pseudo-second-order kinetics. The main advantages of calcium salt as coagulant are good selective, low-cost and high efficiency in precipitating kaolinite particles from slime water systems.
\end{abstract}

Key Words: Kaolinite, Calcium ion, Adsorption, Coal slime water.

\section{INTRODUCTION}

The coal preparation consumes large amount of water, as cleaning 1 ton of coal needs about 3 tons of water circulating. With the increase of raw coal output and selected ratio, quantities of water needed and waste water produced in coal cleaning process are rapidly increasing. If the waste water which we called slime water wasn't effectively treated and was reused circularly, it will cause serious resource waste and environmental pollution. But it is very difficult to settle the slime water, especially for the extreme difficult to clarified slime water systems. Now the extreme difficult to clarified slime water systems occupy about half in total slime water in china. So the treatment of slime water is an important step in coal processing plants, which affects directly the coal quality, economic and environmental efficiency ${ }^{1}$.

Slime water is a highly concentrated micro-solid-liquid suspension-dispersion system which is mainly consisted of clay minerals, such as kaolinite, illite and montmorillonite. The existence of these fine clay particles, especially kaolinite clay, is one of the main reasons why slimes water is difficult to clarify ${ }^{2}$. In recent years, many kinds of flocculation ways have been investigated for precipitating kaolinite particles from slime water $^{3-6}$, but for difficult clarified slime water systems, the system didn't clarify completely after large amount of flocculants were used. Mineral coagulant (mainly gypsum) has excellent sedimentation effects in difficult clarified slime water systems and has been applied in large scale in china ${ }^{7}$, but the reasons why gypsum (effective composition is $\mathrm{Ca}^{2+}$ ) has excellent sedimentation effects on fine clay particles in the slime water have little been reported in literatures. In this paper, we investigated the adsorption thermodynamics and kinetics of $\mathrm{Ca}^{2+}$ onto kaolinite clay and proposed the possible special adsorption mechanism in order to solve the clarification problems of difficult clarified slime water and instruct production process.

\section{EXPERIMENTAL}

All chemicals used were of analytical-laboratory grade and were purchased from Fu Chen Chemical Reagent Factory, Tianjin, China.

Kaolinite samples used were provided by China kaolinite Co. (Suzhou, Jiangsu, China). Particles of kaolinite were passed through a 200 -mesh sieve and were dried at $105{ }^{\circ} \mathrm{C}$. BETspecific surface area measured by $\mathrm{N}_{2}$ adsorptions is $17 \mathrm{~m}^{2} \mathrm{~g}^{-1}$.

The sorption isotherm and kinetics experiments were performed by batch adsorption experiments and were carried out by mixing $1 \mathrm{~g}$ (weighs accurately) of kaolinite with 100 $\mathrm{mL}$ (measures accurately) of $\mathrm{Ca}^{2+}$ solution under natural $\mathrm{pH}$ conditions with electrolyte concentration of $0.2 \mathrm{~mol} / \mathrm{L}$ at a constant speed of $200 \mathrm{rpm}$ in thermostatic oscillation box. After an oscillating time, the suspensions were centrifuged for 
$10 \mathrm{~min}$ at $1500 \mathrm{rpm}$. The supernatants were collected and analyzed for calcium ions concentration.

Stock solutions of calcium were prepared from $\mathrm{CaCl}_{2}$. Working solutions of $\mathrm{Ca}^{2+}$ were prepared from the stock solution to the desired concentrations for each experimental run. The accurate concentrations were measured with calcium ion electrode.

Adsorption capacity of kaolinite was calculated as:

$$
\mathrm{q}_{\mathrm{t}}=\frac{40\left(\mathrm{C}_{0}-\mathrm{C}_{\mathrm{t}}\right) \mathrm{V}}{1000 \mathrm{~m}}
$$

where $\mathrm{q}_{\mathrm{t}}(\mathrm{mg} / \mathrm{g})$ is the adsorption capacity. $\mathrm{C}_{0}$ is the initial $\mathrm{Ca}^{2+}$ concentration and $\mathrm{C}_{\mathrm{t}}(\mathrm{mmol} / \mathrm{L})$ is the $\mathrm{Ca}^{2+}$ concentration. $\mathrm{V}(\mathrm{mL})$ is the volume of the solution and $\mathrm{m}(\mathrm{g})$ is the mass of kaolinite.

Adsorption isotherms were studied on $\mathrm{Ca}^{2+}$ solutions with varying concentrations from $5-80 \mathrm{mmol} / \mathrm{L}$ at four different temperatures, $5,15,25$ and $35^{\circ} \mathrm{C}$, which selected according to the application temperature range in actual coal slime water. The adsorbent dose was $1 \mathrm{~g} / \mathrm{L}$.

Adsorption kinetics was studied on $5.458 \mathrm{mmol} / \mathrm{L}$ initial $\mathrm{Ca}^{2+}$ concentration at 10 and $20^{\circ} \mathrm{C}$ for a certain time of $0-3 \mathrm{~h}$, respectively.

Field trials were performed in Xingtai coal preparation plant in Shanxi province, China.

Detection method: Elemental compositions of kaolinite surface before and after adsorption were analyzed using X-ray photoelectron spectroscopy analysis (XPS). XPS analyses were performed in PHI-5300/ESCA with a monochromatic aluminum $\mathrm{K}_{\alpha} \mathrm{X}$-ray source. All spectra were obtained in fixed analyzer transmission mode with pass energies of 80 and $20 \mathrm{eV}$ being used for the survey and high-resolution scans, respectively. Elemental compositions were calculated from peak areas obtained from the survey spectra using the appropriate sensitivity factors after subtraction of a linear background.

\section{RESULTS AND DISCUSSION}

Adsorption isotherm: Fig. 1 illustrates the effects of $\mathrm{Ca}^{2+}$ concentration onto the adsorption capacity at 5, 15, 25 and $35^{\circ} \mathrm{C}$, respectively. As shown, the equilibrium adsorption capacity increases promptly with increasing $\mathrm{Ca}^{2+}$ concentration at low $\mathrm{Ca}^{2+}$ concentration stage and reaches maximum value and then the adsorption capacity remains unchanged. This indicates that the surface of kaolinite doesn't adsorb any adsorbates when all active surface sites are occupied. The adsorption capacity decreases with the rise in temperature, showing exothermic nature of the adsorption process. A maximum calcium adsorption capacity of $3.127 \mathrm{mg} / \mathrm{g}$ was achieved with $\mathrm{Ca}^{2+}$ concentration of $39.2182 \mathrm{mmol} / \mathrm{L}$ at $5{ }^{\circ} \mathrm{C}$.

The linear forms of Langmuir isotherm ${ }^{8}$ (2) and Freundlich isotherm ${ }^{9}(3)$ are as:

$$
\begin{gathered}
\frac{\mathrm{C}_{\mathrm{e}}}{\mathrm{q}_{\mathrm{e}}}=\frac{1}{\mathrm{Qb}}+\frac{\mathrm{C}_{\mathrm{e}}}{\mathrm{Q}} \\
\ln \mathrm{q}_{\mathrm{e}}=\ln \mathrm{K}_{\mathrm{F}}+\frac{1}{\mathrm{n}} \ln \mathrm{C}_{\mathrm{e}}
\end{gathered}
$$

where $\mathrm{C}_{\mathrm{e}}(\mathrm{mmol} / \mathrm{L})$ is the equilibrium concentration, $\mathrm{q}_{\mathrm{e}}(\mathrm{mg} / \mathrm{g})$ is the equilibrium adsorption capacity, $\mathrm{Q}(\mathrm{mg} / \mathrm{g})$ is the maximum

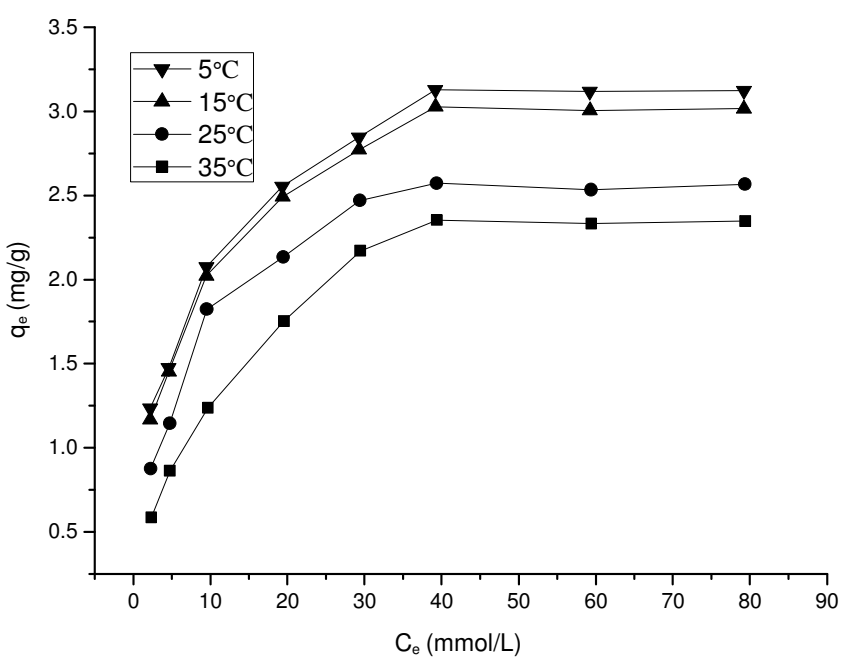

Fig. 1. Effects of $\mathrm{Ca}^{2+}$ concentration on the adsorption capacity at different temperatures

sorption capacity of sorbent, $\mathrm{b}(\mathrm{L} / \mathrm{mmol})$ is the Langmuir constant expressing the adsorption ability. $\mathrm{K}_{\mathrm{F}}$ is the empirical constant of Freundlich isotherm and $\mathrm{n}$ is the empirical parameter related to the intensity of adsorption.

Isotherm constants for each model were determined from the slope and intercept of the linearized plot of the respective isotherm equations. For example, $\mathrm{Q}$ and $\mathrm{b}$ were calculated from the slope and intercept of the linearized plot $\mathrm{C}_{\mathrm{e}} / \mathrm{q}_{\mathrm{e}} v s . \mathrm{C}_{\mathrm{e}}$ shown in Fig. 2. Table-1 shows the values of various isotherm constants and their corresponding correlation coefficients $\left(\mathrm{R}^{2}\right)$ at different temperatures. Excellent fitting lines for Langmuir isotherm equation were obtained at all experimental temperatures studied. The $\mathrm{Q}$ values at different temperatures are close to the experimental equilibrium adsorption capacities and the maximum theoretical $\mathrm{Q}$ value is $3.361 \mathrm{mg} / \mathrm{g}$ at $5{ }^{\circ} \mathrm{C}$, which was little higher than experimental values $(3.127 \mathrm{mg} / \mathrm{g})$. The higher $\mathrm{R}^{2}$ values indicate the applicability of Langmuir isotherm. The results show that the adsorption process of $\mathrm{Ca}^{2+}$ onto kaolinite is mainly monolayer adsorption.

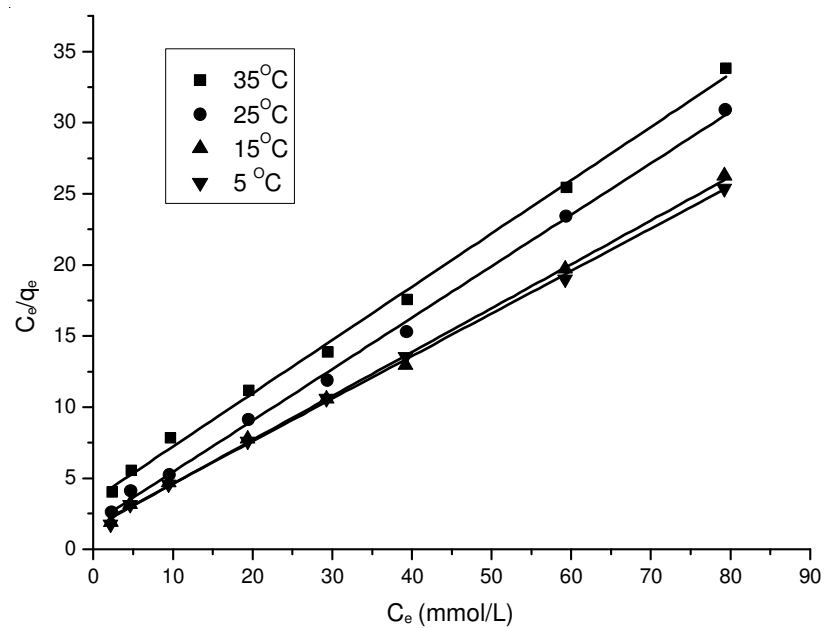

Fig. 2. Plot of the Langmuir isotherm for $\mathrm{Ca}^{2+}$ onto kaolin at different temperatures

Adsorption thermodynamics investigations: Thermodynamic parameters associated with the adsorption, namely 
TABLE-1

LANGMUIR AND FREUNDLICH ISOTHERM PARAMETERS OF CALCIUM SORPTION ONTO KAOLINITE

\begin{tabular}{|c|c|c|c|c|c|c|}
\hline \multirow{2}{*}{ Temperature $\left({ }^{\circ} \mathrm{C}\right)$} & \multicolumn{3}{|c|}{ Langmuir } & \multicolumn{3}{|c|}{ Freundlich } \\
\hline & $\mathrm{Q}(\mathrm{mg} / \mathrm{g})$ & $\mathrm{b}(\mathrm{L} / \mathrm{mmol})$ & $\mathrm{R}^{2}$ & $\mathrm{n}$ & $\mathrm{K}_{\mathrm{F}}\left[(\mathrm{m} / \mathrm{g})(\mathrm{L} / \mathrm{mmol})^{1 / \mathrm{n}}\right]$ & $\mathrm{R}^{2}$ \\
\hline 35 & 2.679 & 0.1105 & 0.99332 & 2.393 & 0.4570 & 0.94166 \\
\hline 25 & 2.764 & 0.1994 & 0.99754 & 3.156 & 0.7559 & 0.89745 \\
\hline 15 & 3.240 & 0.2034 & 0.99811 & 3.521 & 0.9918 & 0.94089 \\
\hline 5 & 3.361 & 0.1975 & 0.99784 & 3.547 & 1.0303 & 0.94553 \\
\hline
\end{tabular}

standard free energy change $\left(\Delta \mathrm{G}^{\mathrm{o}} \mathrm{kJ} \mathrm{mol}^{-1}\right)$, standard enthalpy change $\left(\Delta \mathrm{H}^{\mathrm{o}} \mathrm{kJ} \mathrm{mol}^{-1}\right)$ and standard entropy change $\left(\Delta \mathrm{S}^{\mathrm{o}} \mathrm{J}\right.$ $\mathrm{mol}^{-1} \mathrm{~K}^{-1}$ ), were calculated from the variation of thermodynamic distribution coefficient $K_{d}$ with changes of temperature. $K_{d}$ for the adsorption reaction can be defined as:

$$
\mathrm{K}_{\mathrm{d}}=\lim _{\mathrm{C}_{\mathrm{e}} \rightarrow 0} \frac{\mathrm{C}_{\mathrm{S}}}{\mathrm{C}_{\mathrm{e}}}
$$

where $\mathrm{C}_{\mathrm{s}}(\mathrm{mmol} / \mathrm{g})$ is the $\mathrm{Ca}^{2+}$ concentration on the surface of kaolinite, $\mathrm{C}_{\mathrm{e}}(\mathrm{mmol} / \mathrm{mL})$ is the $\mathrm{Ca}^{2+}$ concentration in the equilibrium suspension, the $\mathrm{K}_{\mathrm{d}}$ can be calculated by plotting $\ln \left(\mathrm{C}_{\mathrm{s}} / \mathrm{C}_{\mathrm{e}}\right)$ vs. $\mathrm{C}_{\mathrm{e}}$ and extrapolating $\mathrm{C}_{\mathrm{e}}$ to zero ${ }^{10}$.

The free energy of sorption process is given as:

$$
\Delta \mathrm{G}^{\mathrm{o}}=-\mathrm{RT} \ln \mathrm{K}_{\mathrm{d}}
$$

The values of $\Delta \mathrm{H}^{\circ}$ and $\Delta \mathrm{S}^{\circ}$ can be calculated from the slope and intercept of a plot of $\ln \mathrm{K}^{\mathrm{o}}$ vs. $1 / \mathrm{T}$ as:

$$
\ln \mathrm{K}_{\mathrm{d}}=-\frac{\Delta \mathrm{H}^{\mathrm{o}}}{\mathrm{RT}}+\frac{\Delta \mathrm{S}^{\mathrm{o}}}{\mathrm{R}}
$$

The calculated values of thermodynamic parameters are shown in Table-2. The negative values of $\Delta \mathrm{G}^{\mathrm{o}}$ confirm the spontaneous nature of calcium sorption. The value of $\Delta \mathrm{H}^{\circ}$ is negative indicating that the sorption process is exothermic in nature. So increasing temperature will be disfavor of the adsorption which is coincident with the result of experiment 3.1. The negative value of $\Delta \mathrm{S}$ corresponds to a decreased degree of freedom in the system as a result of adsorption of $\mathrm{Ca}^{2+}$, as well as decreased randomness at the solid-solution interface reflecting principally the extra translational entropy.

\begin{tabular}{ccccc}
\multicolumn{5}{c}{ TABLE-2 } \\
\multicolumn{5}{c}{ THERMODYNAMIC PARAMETERS } \\
AT DIFFERENT TEMPERATURES \\
\hline $\mathrm{T}(\mathrm{K})$ & $\mathrm{K}_{\mathrm{d}}$ & $\begin{array}{c}\Delta \mathrm{G}^{\mathrm{o}} \\
\left(\mathrm{KJ} \mathrm{mol}^{-1}\right)\end{array}$ & $\begin{array}{c}\Delta \mathrm{S}^{\mathrm{o}} \\
\left(\mathrm{J} \mathrm{mol}^{-1} \mathrm{~K}^{-1}\right)\end{array}$ & $\begin{array}{c}\Delta \mathrm{H}^{\mathrm{o}} \\
\left(\mathrm{KJ} \mathrm{mol}^{-1}\right)\end{array}$ \\
\hline 308 & 9.974 & -5.890 & & \\
298 & 13.464 & -6.442 & -42.825 & -19.156 \\
288 & 18.174 & -6.944 & & \\
278 & 22.198 & -7.165 & & \\
\hline
\end{tabular}

Adsorption kinetics: The kinetics of adsorption process of $\mathrm{Ca}^{2+}$ onto kaolinite was also studied (Fig. 3). The rates of adsorption of $\mathrm{Ca}^{2+}$ onto kaolinite are very fast at the beginning $(0.5 \mathrm{~h})$, then become slow with increase in time because more and more adsorbent surface sites were occupied by the adsorbate molecule/ion. Finally the equilibrium reached.

The pseudo-first-order $(7)^{11}$ and pseudo-second-order $(8)^{12}$ models were employed to explain the solid/liquid adsorption.

$$
\ln \left(\mathrm{q}_{\mathrm{e}}-\mathrm{q}_{\mathrm{t}}\right)=\ln \mathrm{q}_{\mathrm{e}}-\frac{\mathrm{k}_{1}}{2.303} \mathrm{t}
$$

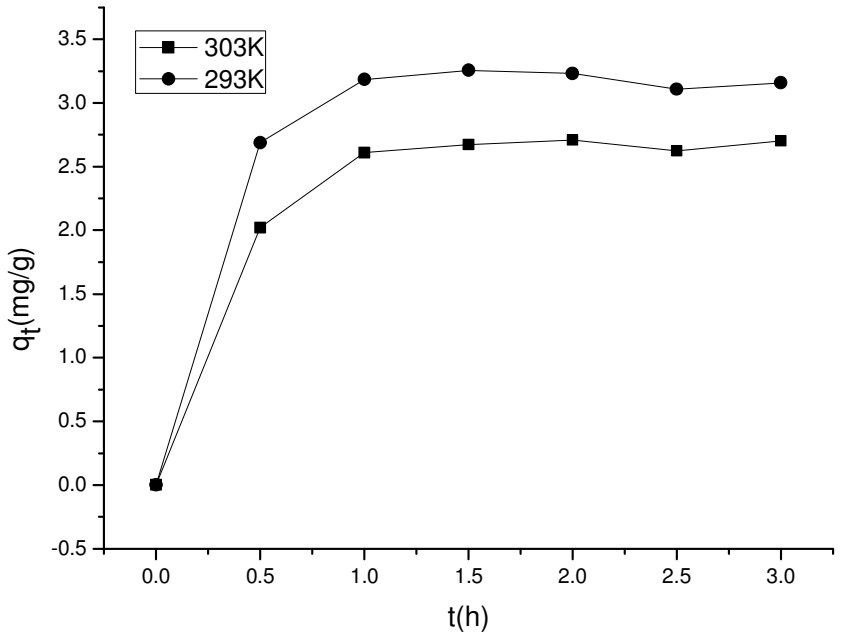

Fig. 3. Adsorption kinetics curves for the adsorption of $\mathrm{Ca}^{2+}$ on kaolin at 293 and $303 \mathrm{~K}$

$$
\frac{\mathrm{t}}{\mathrm{q}_{\mathrm{t}}}=\frac{1}{\mathrm{k}_{2} \mathrm{q}_{\mathrm{e}}^{2}}+\frac{\mathrm{t}}{\mathrm{q}_{\mathrm{e}}}
$$

where $\mathrm{q}_{\mathrm{e}}(\mathrm{mg} / \mathrm{g})$ and $\mathrm{q}_{\mathrm{t}}(\mathrm{mg} / \mathrm{g})$ are the adsorption capacity of $\mathrm{Ca}^{2+}$ adsorbed at equilibrium and at time $\mathrm{t}(\mathrm{h})$, respectively. $\mathrm{k}_{1}$ $\left(\mathrm{h}^{-1}\right)$ is the rate constants of pseudo-first-order. The values of the rate constants $\left(\mathrm{k}_{1}\right)$ were obtained from the slope of the straight-line plots of $\ln \left(\mathrm{q}_{\mathrm{e}}-\mathrm{q}_{\mathrm{t}}\right)$ vs. $\mathrm{t}$ at different temperature. $\mathrm{k}_{2}(\mathrm{~g} /(\mathrm{mg} \mathrm{h}))$ is the rate constant of pseudo-second-order. The values of $\mathrm{q}_{\mathrm{e}}(1 /$ slope $)$ and $\mathrm{k}$ (slope $\mathrm{s}^{2}$ /intercept) of the pseudosecond-order equation can be found out by plotting $\mathrm{t} / \mathrm{q}_{\mathrm{t}} v s . \mathrm{t}$ shown in Fig. 4.

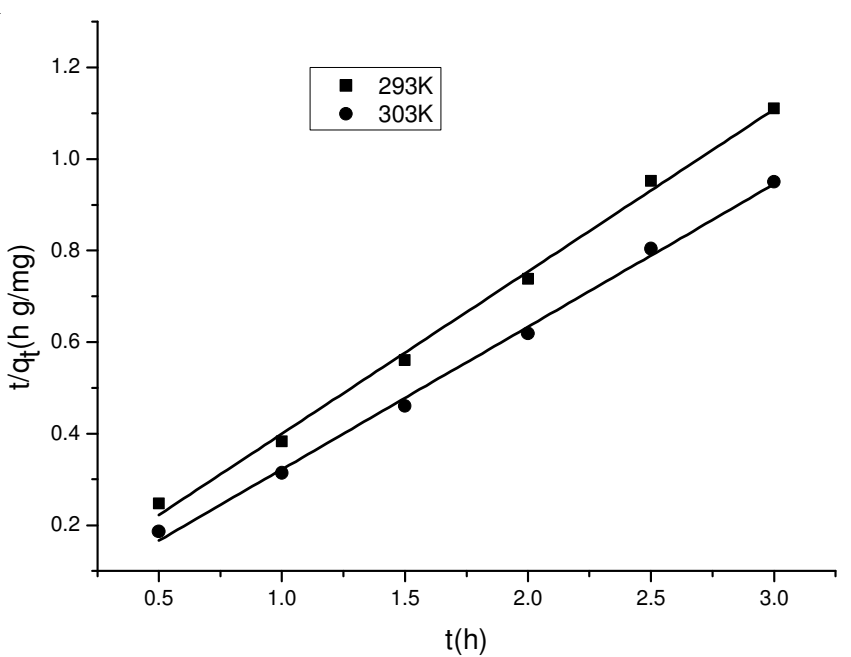

Fig. 4. Pseudo-second-order plot of $\mathrm{Ca}^{2+}$ on kaolin at 293 and $303 \mathrm{~K}$

The rate constants $\left(\mathrm{k}_{1}\right.$ and $\left.\mathrm{k}_{2}\right)$ and correlation coefficients $\left(\mathrm{R}^{2}\right)$ fitting to two models present in Table-3. The high values 


\begin{tabular}{ccccc}
\hline \multicolumn{5}{c}{ TABLE-3 } \\
\multicolumn{5}{c}{ ADSORPTION KINETICS EQUATIONS SIMULATE } \\
& $\mathrm{OF} \mathrm{Ca}^{2+}$ AT DIFFERENT TEMPERATURES \\
\hline \multirow{2}{*}{$\mathrm{T}(\mathrm{K})$} & \multicolumn{2}{c}{ Pseudo-first-order } & \multicolumn{2}{c}{ Pseudo-second-order } \\
\cline { 2 - 5 } & $\mathrm{k}_{1}\left(\mathrm{~h}^{-1}\right)$ & $\mathrm{R}^{2}$ & $\mathrm{k}_{2}(\mathrm{~g} /(\mathrm{mg} \mathrm{h}))$ & $\mathrm{R}^{2}$ \\
\hline 293 & 0.880 & 0.3130 & 8.299 & 0.9989 \\
303 & 0.185 & 0.5000 & 12.859 & 0.9927 \\
\hline
\end{tabular}

of $R_{2}^{2}(0.9989,0.9927)$ for all temperatures indicate that the adsorption data fit well to pseudo-second-order kinetics for the entire adsorption process.

Adsorption mechanism: Kaolinite consists of 1:1 Si-O tetrahedron and $\mathrm{Al}-\mathrm{O}$ octahedron ${ }^{13}$. Si-O tetrahedron and $\mathrm{Al}-\mathrm{O}$ octahedron share oxygen atoms. Inner and inner surface hydroxyl groups easily form hydrogen bonds, so the kaolinite structure is stable. The basal planes ( $00 \overline{1}$ and 001) of kaolinite are constantly taken a little negative charge, due to the isomorphous substitution of $\mathrm{Al}^{3+}$ for $\mathrm{Si}^{4+}$ and $\mathrm{Mg}^{2+}$ for $\mathrm{Al}^{3+}$. So there are electrostatic attraction between $\mathrm{Ca}^{2+}$ and kaolinite, but it was not occupied dominant interaction in adsorption process because of the low isomorphous substitution quantities decided by the structure of kaolinite. The results of experiments and adsorption isotherm analyses (Section 3.1) also confirm this point.

As the normal $\mathrm{pH}$ value in the system is $6-9, \mathrm{Ca}^{2+}$ may be converted to $\mathrm{CaOH}^{+}$as shown in Fig. $5^{14}$. The surface charge of kaolinite becomes less negative and the surface of kaolinite particles appears a lot of $\equiv \mathrm{SiOH}$ and $>\mathrm{AlOH}$ active groups. It is deduced that the hydroxyl group complexing reaction occurred as follows $((9),(10))$ in adsorption process.

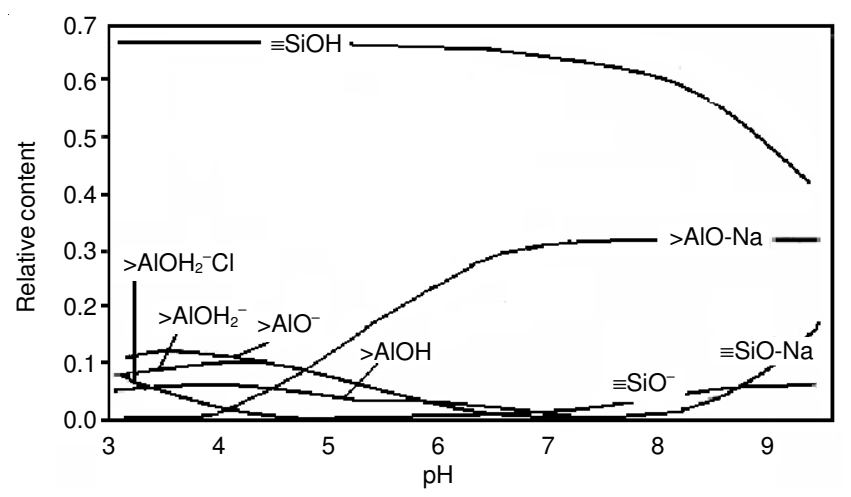

Fig. 5. Variation of the relative content of groups on kaolinite surface with $\mathrm{pH}$ value

$$
\begin{aligned}
>\mathrm{AlOH}+\mathrm{CaOH}^{+} & \rightarrow>\mathrm{Al}-\mathrm{OHHOCa}^{+} \\
& \rightarrow \mathrm{Al}-\mathrm{OCa}^{+}+\mathrm{H}_{2} \mathrm{O} \\
\equiv \mathrm{SiOH}+\mathrm{CaOH}^{+} & \rightarrow \equiv \mathrm{Si}-\mathrm{OHHOCa}^{+} \\
& \rightarrow \equiv \mathrm{Si}-\mathrm{OCa}^{+}+\mathrm{H}_{2} \mathrm{O}
\end{aligned}
$$

It was suggested that the hydroxyl group complexing reaction plays a relatively important role compared to electrostatic interaction in adsorption process.

Table-4 gave the elemental relative composition of kaolinite surface before and after adsorption characterized by XPS. The calcium content in raw clay is very little, only occupied

\begin{tabular}{lccccc}
\hline \multicolumn{6}{c}{ TABLE-4 } \\
ELEMENTAL COMPOSITION (\%) OF KAOLINITE \\
BEFORE AND AFTER ADSORPTION
\end{tabular}

$0.1 \%$ of total quantities, but it increased to $1.09 \%$ after adsorbed indicating that calcium in the solution was adsorbed onto the kaolinite surface, which also demonstrated the occurrence of complexing reactions.

The special adsorption of $\mathrm{Ca}^{2+}$ onto kaolinite is crucial important for the selective aggregation and flotation in slime water system, especially for difficult clarified slime water systems. The quality of circulating water in coal preparation process affects the quality and ash of fine coal. Excess agents in circulating water can affect the flotation effects. The aggregating agents with poor selectivity precipitate coal and minerals at the same time and lead to ash decreasing in the tailings and fine coal lost. Calcium salt as aggregating agent can especially adsorb onto the surface of kaolinite and form the selective aggregation, which is in favour of quantifying agents and improving separation effects.

\section{Conclusion}

The adsorption nature of $\mathrm{Ca}^{2+}$ on kaolinite is spontaneous and exothermic. The adsorption data follow Langmuir isotherms. The possible adsorption mechanism is that $\mathrm{CaOH}^{+}$in the system reacted with $\equiv \mathrm{SiOH}$ and $>\mathrm{AlOH}$ groups appeared in the surface of kaolinite. Sorption is mainly controlled by pseudo-secondorder kinetics.

\section{ACKNOWLEDGEMENTS}

The authors are grateful to National Basic Research Program of China (973 Program) (Grant No. 2012CB214901), the Fundamental Research Funds for the Central Universities (Grant No. 2010LKHX07) and National Natural Science Foundation of China (Grant No. 50921002, 51274197) for the financial support to this work.

\section{REFERENCES}

1. J. Liu, M.Q. Zhang, S.J. Zhang, L. Feng, Z. Ou and X.B. Li, The Sedimentation Characteristics of Coal Slime Water and Water Hardness, In International Coal Preparation Congress, Conference Proceedings, pp. 898-903 (2010)

2. L. Feng, J. Liu, M. Zhang and L. Song, J. China Univ. Mining Technol., 39, 671 (2010).

3. S. Cao et al., J. China Univ. Mining Technol., 38, 410 (2009).

4. J. Chen, Y. Li, C. Wang and X. Zhang, Liaoning Chem. Ind., 33, 477 (2004).

5. J. Li, Coal Processing Comprehensive Utilization, 31 (2006).

6. Z. Lin, C. Yang, Z. Shen and X. Qi, J. China Coal Soc., 35, 312 (2010).

7. J. Liu, M. Zhang and Y. Zeng, J. China Univ. Mining Technol., 39, 59 (2010).

8. I. Langmuir, J. Am. Chem. Soc., 38, 2221 (1916).

9. H.M.F. Freundlich, Z Phys. Chem., 57, 385 (1906).

10. A.A. Khan and R.P. Singh, Colloids Surf., 24, 33 (1987).

11. S. Lagergren, Kungliga Svenska Vetenskapsakademiens. Handlingar, 24, 1 (1898).

12. Y.S. Ho, Water Res., 40, 119 (2006)

13. D.L. Bish and R.B. Von Dreele, Clays Clay Miner., 37, 289 (1989).

14. M. Zhang, China University of Mining \& Technology (2006). 